\title{
Effects of Low-to-Moderate Doses of Anabolic Steroids on Lipid Profile and Muscle Hypertrophy in Resistance Training Practitioners: A Systematic Review with Meta-Analysis
}

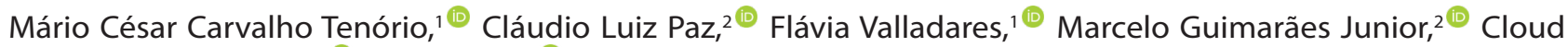
Kennedy Couto de Sá, ${ }^{\circledR}{ }^{\circledR}$ Luis Correia ${ }^{1}$

Escola Bahiana de Medicina e Saúde Pública,' Salvador, BA - Brazil

Faculdade Social da Bahia, ${ }^{2}$ Salvador, BA-Brazil

Universidade Estadual de Feira de Santana, ${ }^{3}$ Feira de Santana, BA - Brazil

\section{Abstract}

Background: The use of androgenic anabolic steroids (AAS) is prevalent among young bodybuilders, motivated by aesthetic results. Although the medical community condemns this practice for its potential deleterious effect, we must recognize the need for more scientific research on the likelihood and magnitude of the adverse events.

Objective: To evaluate whether high-quality, scientific evidence supports that AAS negatively affect lipid profile and promote muscle hypertrophy in resistance training practitioners.

Methods: A systematic review of the literature of randomized clinical trials was conducted in the PubMed / Medline, Scielo and Science direct databases. The searches were conducted by two independent researchers by June 2018. A significance level of $5 \%$ was considered in the analysis.

Results: Six clinical trials involving 170 resistance training practitioners were included. A significant heterogeneity was found in studies evaluating the effects of AAS on lipid profile and muscle hypertrophy $\left(\mathrm{I}^{2}=97,95\right.$ and $91 \%$, respectively), with no significant effects on HDL-cholesterol $(-5.62 \mathrm{mg} / \mathrm{dL}, 95 \% \mathrm{CI}-12.10,0.86, \mathrm{p}=0.09)$, LDLcholesterol $(7.76 \mathrm{mg} / \mathrm{dL}, 95 \% \mathrm{CI}-9.70,25.23, \mathrm{p}=0.57)$ and muscle hypertrophy $(2.44 \mathrm{~kg} 95 \% \mathrm{CI} 0.02,4.86, \mathrm{p}=0.05)$.

Conclusion: Current evidence does not support that low-to-moderate doses of AAS cause serious negative effects on lipid profile or promote muscle hypertrophy in resistance training practitioners.

Keywords: Receptors Androgen; Young Adult; Esthetics; testosterone Congeners; Resistance Training.

\section{Introduction}

After the discovery of the effects of testosterone on muscle strength and hypertrophy, a synthetic formula of this hormone was developed in the late 1930s and came to be called androgenic-anabolic steroids (AAS). ${ }^{1}$ These drugs have been used legally by particular individuals, such as the elderly, patients with acquired immunodeficiency syndrome, hypogonadism, anemia that accompanies renal failure, bone marrow failure, endometriosis, cancer and osteoporosis. ${ }^{2}$
The use of AAS by young sports practitioners has increased due to the need to obtain results in the short term, such as breaking records in competitions, and for muscle hypertrophy, either for aesthetic or bodybuilding purposes..$^{3,4}$ However, these substances are known to be associated with adverse effects, including acne, testicular atrophy, mood changes, water retention and gynecomastia. The prevalence of use of AAS varies across geographic regions, ranging from $0.2 \%$ in Asia, $4.8 \%$ in South America, reaching 21.7\% in the Middle East. ${ }^{5}$

In addition, biochemical changes induced by AAS can promote changes in the lipid profile, characterized by a

Mailing Address: Mário César Tenório

Av. Dom João VI, n²75. Postal Code: 40290-000, Brotas, Salvador, BA - Brazil.

E-mail: mariocesartenorio@hotmail.com 
decrease in high-density lipoprotein cholesterol (HDL-c) levels and increase in low-density lipoprotein cholesterol (LDL-c) levels by changes in apolipoproteins AI, synthesis of apolipoprotein $\mathrm{B}$, and activation of hepatic lipase. Changes in lipid and lipoprotein metabolism are risk factors for atherosclerotic disease and risk predictors of coronary artery disease and cerebrovascular disease, ${ }^{6}$ and therefore, AAS-induced changes in lipid metabolism can increase the risk of acute myocardial infarction and sudden death. ${ }^{7}$

Despite these cardiovascular ${ }^{8}$ and metabolic ${ }^{1}$ problems associated with the use of ASS, some authors have questioned this association due to the reduced number of randomized clinical trials on this subject, ${ }^{9}$ mainly for ethical reasons involved in studies with young athletes or practitioners of physical exercises. ${ }^{10}$

In parallel, we observed that there is a conflict in the literature regarding which AAS and doses would cause greater changes in lipid profile, and which ones would be safer from the risk-benefit point of view. ${ }^{11-13}$ Other factors known to affect influence lipid levels must also be considered, such as genetic rearrangements and users' diet. ${ }^{14,15}$

Therefore, the purpose of this review was to assess whether high-quality scientific evidence supports that AAS negatively affects the lipid profile and promotes muscle hypertrophy in resistance trainers.

\section{Methods}

A systematic review of the literature was carried out following the preferred reporting items for systematic review and meta-analysis protocols (PRISMA-P) statement. ${ }^{16}$ The review protocol was registered in PROSPERO (CRD 42018086525).

\section{Literature Search Strategy}

The databases used were PubMed / Medline, Scielo, and Science direct, and the following Mesh terms and names of the main AAS used in the search: "anabolic androgenic steroids"; "testosterone congeners"; "testosterone"; "resistance training"; "strength training"; "resistance exercise"; "strength exercise"; "HDL"; "LDL"; "lipoprotein"; "triglycerides", using the Boolean operator "and". In addition, all terms were translated into Portuguese and used for searches in Portuguese language databases. The searches ended in June 2018.

\section{Inclusion and Exclusion Criteria}

The inclusion criteria for the articles were: randomized clinical trials that evaluated the effects of AAS in healthy adults who did resistance training and were evaluated for the following outcomes: HDL, LDL, TG and muscle hypertrophy. Articles that did not use control groups, that did not present a detailed description of the resistance training program, and studies including patients that used any medication that could influence the lipid profile were excluded.

The Kappa coefficient was calculated to identify the level of agreement between researchers.

\section{Data Collection}

Two independent researchers (M.C.C.T and C.L.S.L.P) selected the articles by titles, excluding those that did not address the proposed theme. Then, the abstracts were analyzed to identify the articles that met the inclusion criteria.

Subsequently, studies that met the inclusion criteria were selected for systematic review and subsequent meta-analysis. In case of divergence, a third researcher (C.K.C.S) was consulted. The relevant data were extracted from the included studies by two independent reviewers (CLSLP and MCCT) - mean \pm standard deviation (SD) of pre- and post-intervention period, and changes from baseline (post-test - pre-test) and pooled SD. Data presented in $\mathrm{mmoL} / \mathrm{L}$ were converted to $\mathrm{mg} / \mathrm{dL}$.

The studies that did not present grouped SD of one of the interventions had their values estimated through p-value, confidence interval, or correlation coefficient, and a correlation of $\mathrm{R}=0.80$ was adopted in the calculations. ${ }^{17}$

\section{Risk of Bias}

The risk of bias was assessed by the Cochrane Collaboration's Risk of Bias Tool 1.0. The tool was used in its full version, with no insertions or changes in any of its seven domains ${ }^{18}$ which were assessed independently by two reviewers (M.C.C.T and C.L.S.L.P).

The following domains were considered for bias assessment: (a) selection bias due to the generation of random sequence, (b) selection bias due to allocation concealment, (c) performance bias, (d) detection bias, (e) attrition bias, (f) reporting bias and (g) other bias. The supporting material of the RoB 1.0 tool (no internal assumptions were made) was used as support for the 
evaluation of the domains. Discrepancies were resolved by consensus between the reviewers. The data are shown in Figure 6.

\section{Meta-analysis}

The meta-analyses were conducted using the Review Manager software (RevMan 5.3. Copenhagen: The Nordic Cochrane Center, The Cochrane Collaboration, 2014). Random effect models with inverse variance method for continuous data were adopted, and data were expressed as difference of means and confidence intervals $(95 \% \mathrm{CI})$. The heterogeneity between the studies was calculated using Cochrane's $\mathrm{Q}$ analysis with a statistical significance level of 0.10 for heterogeneity, and the $\mathrm{I}^{2}$ for inconsistencies in treatment effect sizes ( $\mathrm{I}^{2}>50 \%$ accepted for substantial heterogeneity). ${ }^{19}$ For exploration of heterogeneity among studies, each study was removed one at a time to verify whether it was a potential cause of heterogeneity. Kappa statistics were performed using SPSS software version 21 to identify the agreement in the selection of studies, and analysis of the methodological quality evaluated by the Risk of Bias Tool 1.0 tool from the Cochrane Collaboration. Accuracy of searches was analyzed by dividing the number of articles included by the number of articles selected was divided after duplicates were removed. Subsequently, the NNR (Number needed to read) = 1 / precision was calculated, according to Lee et al. ${ }^{20}$.

\section{Results}

After the search was complete, 9,767 articles were retrieved from the databases. Then, 6,257 duplicate articles were excluded. After reading the titles, 3,244 articles were excluded and 228 were excluded after reading the abstracts. Thus, 38 articles were selected for full reading. Then, 32 articles were excluded - 11 for not being randomized, 9 for not having evaluated the lipid profile, 7 for not having described the use of RT, 3 for the population included in the study (elderly individuals on hormone replacement therapy), 1 for not having a control group and 1 for including substances that were not AAS in the experimental group. Therefore, 6 studies were included in the qualitative and quantitative analyses (Figure 1). A Kappa index of 0.67 was found between the two evaluators. The search precision was 0.0014 and the NNR was 714 .

\section{Risk of bias}

Based on the Cochrane collaboration tool for assessment of controlled clinical trials, no study was judged as low risk of bias (Figure 6).

As for the selection bias (randomization and allocation concealment), all studies were classified as "risk of uncertain bias". For performance (accreditation of participants and professionals), approximately $33.3 \%$ of the studies ${ }^{11,21}$ were classified as "low risk".

In the assessment of detection bias (blinding of evaluators), only one study was classified as low risk. ${ }^{11}$

Approximately $50 \%$ of the studies were classified as "high risk" for "attrition bias" (incomplete outcomes). ${ }^{11,21,22}$ Four studies $(66.7 \%)$ were classified as low risk for reporting bias (selective outcome report) $)^{12,21,23,24}$ and two were classified as risk of uncertain bias. ${ }^{11,22}$ Only two studies were classified as low risk for other biases, ${ }^{21,23}$ the others were classified as risk of uncertain bias.

It should be noted that the studies included had a small sample size and did not describe the evaluation of statistical power, allowing random errors due to low power.

In domain assessment, the Kappa coefficient for agreement between the two reviewers was 0.70 .

\section{Characteristics of Studies and Participants}

General description of the included studies is summarized in Table 1. In total, 170 individuals completed the studies with RT, mean sample size 22.3 \pm 12.5 , and age range between 18 and 65 years. The highest mean age reported was 47 years. ${ }^{22}$ Four studies evaluated trained individuals, ${ }^{11,21,23,24}$ only one study included sedentary individuals, ${ }^{12}$ and one study did not describe the physical activity status of participants, whether experienced practitioners or beginners. ${ }^{22}$ In the meta-analysis, the number of subjects evaluated was 134, 54, 67 and 133 for the outcomes HDL, LDL, triglycerides and muscle hypertrophy, respectively. Of the included studies, one study evaluated lipid profile as the primary objective, ${ }^{23}$ one study did not describe dietary control/ guidance, ${ }^{24}$ two studies reported adverse effects related to acne, nipple tenderness, ${ }^{11}$ headaches, muscle cramps, dehydration and mood swings. ${ }^{21}$ One study presented the calculation of sampling power a posteriori for its main outcome, ${ }^{22}$ but no study presented a sample calculation for the analyzed outcomes; all studies showed multiple comparisons. The study by Bhasin et al. ${ }^{11}$ used 


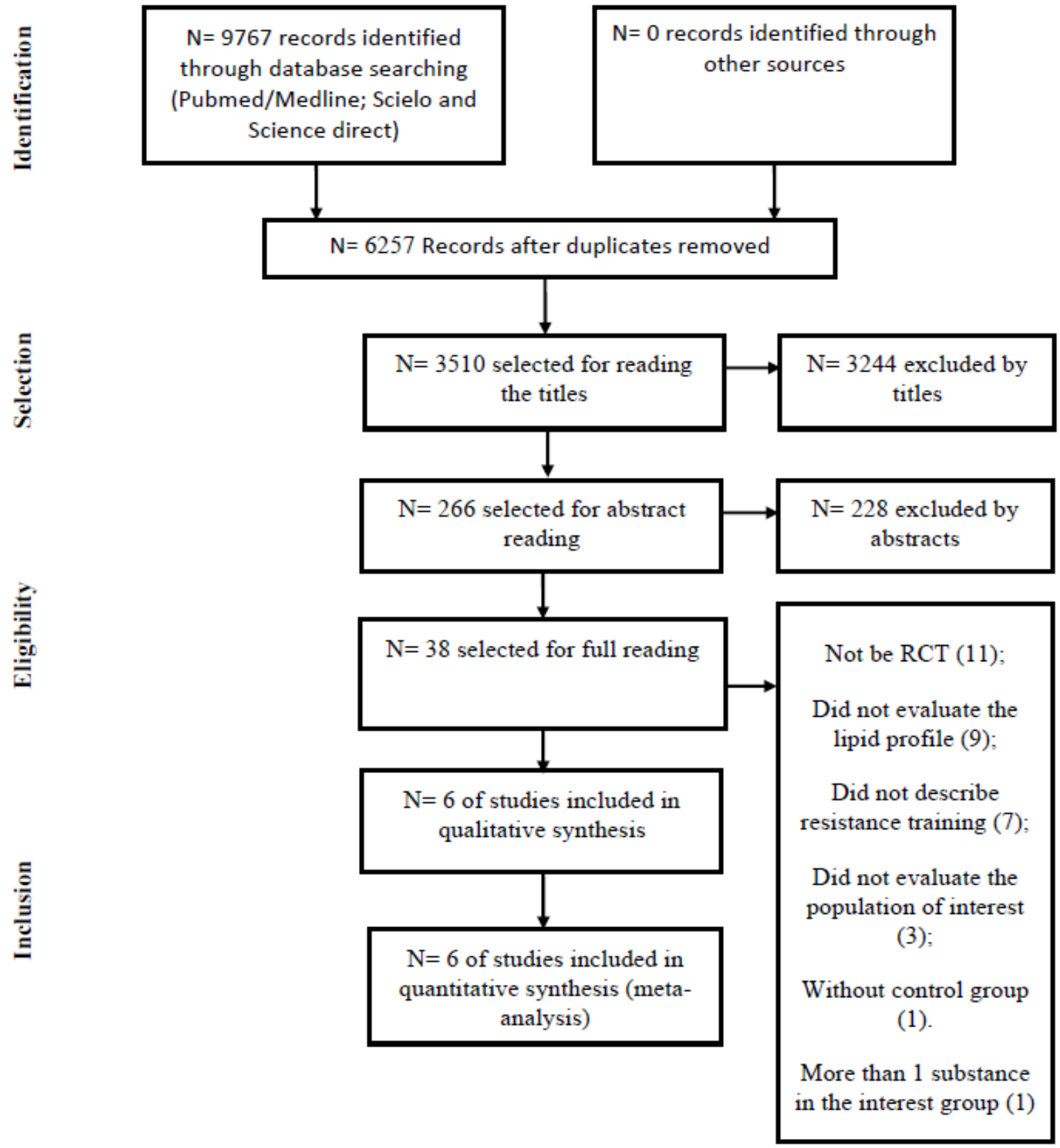

Figure 1 - Flowchart of study selection.

different samples for the analysis of lipid profile and anthropometric outcomes.

\section{Characteristics of the Interventions}

Interventions lasted from 4 to 12 weeks, with a weekly frequency of 3-4 sessions per week. Regarding the doseresponse of strength training, the volume varied from 3 to 5 sets per exercise of 3-15 repetitions at an intensity of 65 to $95 \%$ of a maximum repetition. Only Broeder et al. ${ }^{22}$ used a non-linear (wave) periodization.

AAS doses were applied intramuscularly weekly ${ }^{11,23,24}$ or as capsules consumed two to three times a day, every day. ${ }^{12,21,22}$ The doses of injectable steroids ranged from $200 \mathrm{mg} /$ week of testosterone decanoate ${ }^{23,24}$ to $600 \mathrm{mg} /$ week of testosterone enanthate. ${ }^{11}$ Only the study by 


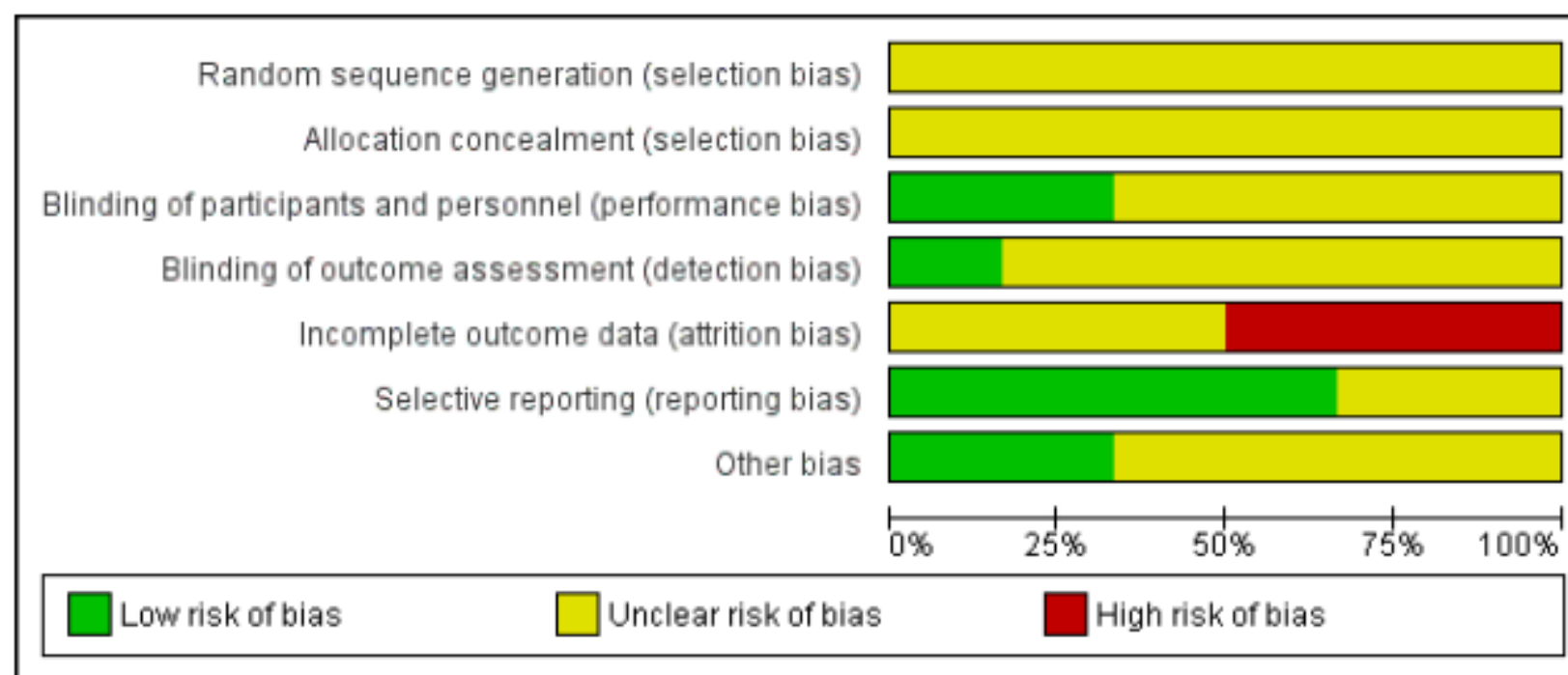

Figure 2 - Bias risk assessment.

Bashin et al. ${ }^{11}$ used supraphysiological doses. Control groups received weekly intramuscular administration of sesame oil ${ }^{11}$ or peanut oil ${ }^{23}$ or consumed rice flour- ${ }^{12}$ maize starch- ${ }^{22}$ or maltodextrin- derived placebos. ${ }^{21}$ The study by Kuipers et al. ${ }^{24}$ did not report the substance used as a placebo.

\section{AAS and HDL}

Six studies were included in the statistical analysis, which revealed substantial heterogeneity $\left(I^{2}=97 \%\right)$ among the studies. Three of the six studies showed no effects on HDL, ${ }^{11,23,24}$ and three ${ }^{12,21,22}$ showed changes in HDL levels, with only one reporting a great reduction. ${ }^{21}$ All these studies that showed changes in HDL levels used oral prohormone drugs, whereas studies that used injectable drugs did not show changes in HDL. In the subgroup analysis, no heterogeneity was found between the studies that used injection drugs $\left(\mathrm{I}^{2}=0 \%, \mathrm{p}=0.46\right)$; however, considerable heterogeneity was found in the analysis of the studies that used oral drugs $\left(I^{2}=97 \%\right.$, $p$ $<0.001$ ).

No changes in HDL were identified with the use of oral or injectable substances $(-9.33 \mathrm{mg} / \mathrm{dL}, 95 \% \mathrm{CI}-18.30$, $-0.36, \mathrm{p}<0.00001 ; \mathrm{I}^{2}=97 \%$ and $0.75 \mathrm{mg} / \mathrm{dL}, 95 \% \mathrm{CI}-0.93$, $2.42, \mathrm{p}=0.46 ; \mathrm{I}^{2}=0 \%$, respectively).

As shown in Figure 2, in the total analysis, no significant difference was found in HDL-c reduction for AAS groups (-5.62mg/dL, 95\%CI -12.10, 0.86, $\mathrm{p}=0.09$; $\mathrm{I}^{2}$
$=97 \%)$. In general, an average decrease of $6.2 \pm 6.1 \mathrm{mg} / \mathrm{dL}$ was observed in the AAS group after the intervention, while a decrease by $0.8 \pm 3.0 \mathrm{mg} / \mathrm{dL}$ was observed in the control group. No great methodological heterogeneity was identified in the studies.

\section{AAS and LDL}

Three studies that evaluated LDL-c levels were included in the statistical analysis. The meta-analysis revealed considerable heterogeneity among the studies $\left(\mathrm{I}^{2}=95 \%\right)$. Only one study reported a reduction in LDL-c levels, ${ }^{11}$ and only the study by Granados et al. ${ }^{21}$ showed a significant increase. Due to the limited number of studies evaluating changes in this outcome, it was not possible to perform a sensitivity analysis of the substances used.

As shown in Figure 3, no significant difference was found in LDL values between AAS and control groups (7.76mg/dL, 95\%CI -9.70, 25.23, p=0.57; $\left.\mathrm{I}^{2}=95 \%\right)$. In general, an average change of $9.1 \pm 18.2 \mathrm{mg}$ and $0.9 \pm 4.2 \mathrm{mg}$ in LDL was found in the AAS group and control groups, respectively, after the interventions.

\section{AAS and Triglycerides}

Four studies were included in the statistical analysis. It was not possible to perform a sensitivity analysis of the substances used. In the total analysis, as shown in Figure 4 , there was a statistically significant difference in the 


\begin{tabular}{|c|c|c|c|c|c|c|c|c|c|}
\hline \multirow{2}{*}{$\begin{array}{l}\text { Study or Subgroup } \\
\text { 6.1.1 Prohormonio }\end{array}$} & Mean [mg/dl] & AAS & \multicolumn{4}{|c|}{ Control } & Weight & $\begin{array}{c}\text { Mean Difference } \\
\text { N, Random, } 95 \% \mathrm{Cl}[\mathrm{mg} / \mathrm{dl}]\end{array}$ & $\begin{array}{c}\text { Mean Difference } \\
\text { N, Random, } 95 \% \mathrm{Cl}[\mathrm{mg} / \mathrm{dl}]\end{array}$ \\
\hline & & & & & & & & & \\
\hline Broeder et al., 2000 & -2.7291 & 6.1378 & 32 & 2.32 & 7.77 & 18 & $17.4 \%$ & $-5.05[-9.22,-0.88]$ & $\rightarrow-$ \\
\hline Granados et al 2014 & -18.7 & 3 & 9 & -0.9 & 2.3 & 8 & $18.2 \%$ & $-17.80[-20.33,-15.27]$ & 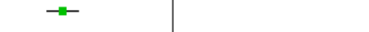 \\
\hline $\begin{array}{l}\text { King et al., } 1999 \\
\text { Subtotal } \mathbf{9 5 \%} \mathbf{C l})\end{array}$ & -5.01 & 1.95 & $\begin{array}{r}9 \\
50\end{array}$ & 0 & 1.93 & $\begin{array}{l}10 \\
36\end{array}$ & $\begin{array}{l}18.4 \% \\
54.0 \%\end{array}$ & $\begin{array}{r}-5.01[-6.76,-3.26] \\
-9.33[-18.30,-0.36]\end{array}$ & \\
\hline \multicolumn{10}{|c|}{$\begin{array}{l}\text { Heterogeneity: } \text { Tau }^{2}=60.51 ; C h i^{2}=69.92, d f=2(P<0.00001) ; I^{2}=97 \% \\
\text { Test for overall effect: } Z=2.04(P=0.04)\end{array}$} \\
\hline \multicolumn{10}{|l|}{ 6.1.2 Injectable } \\
\hline Bhasin et al, 1996 & -4 & 1.84 & 10 & -5 & 1.9 & 8 & $18.4 \%$ & $1.00[-0.74,2.74]$ & - \\
\hline Hartgens et al., 2004 & -2.7 & 8.43 & 9 & 2.31 & 10.89 & 7 & $13.1 \%$ & $-5.01[-14.78,4.76]$ & - \\
\hline Kuipers et al.,1991 & -4.64 & 7.04 & 8 & -3.86 & 8.12 & 6 & $14.4 \%$ & $-0.78[-8.90,7.34]$ & 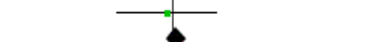 \\
\hline \multicolumn{10}{|c|}{$\begin{array}{l}\text { Heterogeneity: } \operatorname{Tau}^{2}=0.00 ; \mathrm{Chi}^{2}=1.55, \mathrm{df}=2(\mathrm{P}=0.46) ; \mathrm{I}^{2}=0 \% \\
\text { Test for overall effect: } Z=0.87(P=0.38)\end{array}$} \\
\hline Total $(95 \% \mathrm{Cl})$ & & & 77 & & & 57 & $100.0 \%$ & $-5.62[-12.10,0.86]$ & \\
\hline $\begin{array}{l}\text { Heterogeneity: } \operatorname{Tau}^{2}= \\
\text { Test for overall effect: } \\
\text { Test for subqroup diffe }\end{array}$ & $\begin{array}{l}8.44 ; \mathrm{Chi}^{2}=145 \\
=1.70(P=0.09 \\
\text { ences: } \mathrm{Chi}^{2}=4 .\end{array}$ & $\begin{array}{l}64, d f=5(P \\
69, d f=1(P\end{array}$ & $\begin{array}{l}<<0.00 \\
=0.03)\end{array}$ & $\begin{array}{l}001) ; I^{2}=97 \% \\
I^{2}=78.7 \%\end{array}$ & & & & & $\begin{array}{ccccc}1 & 1 & 1 & 1 \\
-20 & -10 & 0 & 10 & 20 \\
\text { Lower HDL-C AAS } & \text { Lower HDL-C Control }\end{array}$ \\
\hline
\end{tabular}

\begin{tabular}{|c|c|c|c|c|c|c|c|c|c|c|c|}
\hline \multirow[b]{2}{*}{ Study or Subgroup } & \multicolumn{3}{|c|}{ AAS } & \multicolumn{3}{|c|}{ Control } & \multicolumn{2}{|c|}{ Mean Difference } & \multirow{2}{*}{\multicolumn{3}{|c|}{$\begin{array}{l}\text { Mean Difference } \\
\text { IV, Random, } 95 \% \mathrm{Cl}\end{array}$}} \\
\hline & Mean & SD & Total & Mean & SD & Total & Weight & N, Random, 95\% Cl & & & \\
\hline Bhasin et al, 1996 & -7 & 7.2 & 10 & -2 & 4.2 & 8 & $34.1 \%$ & $-5.00[-10.33,0.33]$ & & $\rightarrow-1$ & \\
\hline Granados et al 2014 & 29 & 12.3 & 9 & -0.9 & 6.2 & 8 & $32.1 \%$ & $29.90[20.79,39.01]$ & & $\rightarrow-$ & \\
\hline King et al., 1999 & 5.41 & 7.3 & 9 & 5.79 & 5.3 & 10 & $33.9 \%$ & $-0.38[-6.17,5.41]$ & & $-1+$ & \\
\hline Total $(95 \% \mathrm{Cl})$ & & & 28 & & & 26 & $100.0 \%$ & $7.76[-9.70,25.23]$ & & & \\
\hline $\begin{array}{l}\text { Heterogeneity: Tau }{ }^{2}= \\
\text { Test for overall effect: }\end{array}$ & $\begin{array}{l}25.84 ; 0 \\
=0.87\end{array}$ & $\begin{array}{l}C h i^{2}=4 \\
P=0.3\end{array}$ & 43.28, d & $d f=2(P$ & $<0.00$ & $0001) ;$ & $1^{2}=95 \%$ & & -100 & $\begin{array}{ccc}-50 & 0 & 50 \\
\text { Higher LDL-C Control } & \text { Higher LDL-C Control }\end{array}$ & 100 \\
\hline
\end{tabular}

reduction of triglycerides for the steroid group $(-11.68 \mathrm{mg} /$ $\left.\mathrm{dL}, 95 \% \mathrm{CI}-23.07,-0.26, \mathrm{p}=0.04 ; \mathrm{I}^{2}=42 \%\right)$. In general an average decrease of $5.6 \pm 24.2 \mathrm{mg} / \mathrm{dL}$ and $0.8 \pm 14.4 \mathrm{mg} / \mathrm{dL}$ in triglyceride levels was observed in AAS group and control group, respectively, after the interventions.

\section{AAS and Hypertrophy}

Considering the effects of AAS on muscle hypertrophy, considerable heterogeneity was demonstrated $\left(\mathrm{I}^{2}=91 \%\right.$, $\mathrm{p}<0.00001)$ among the studies analyzed. Of the studies that evaluated the effects of AAS on lipid profile, four evaluated muscle hypertrophy, of which, two did not demonstrate hypertrophic changes. ${ }^{12,22}$ As shown in Figure 5 , there was no statistical difference in muscle hypertrophy between AAS and placebo groups $( \pm 2.44 \mathrm{~kg}$; $95 \mathrm{CI} \% 0.02$; $4.86, \mathrm{p}=0.05)$. The experimental group obtained an average hypertrophic increase of $3.7 \pm 2.0 \mathrm{~kg}$ after the intervention, while the control group obtained an increase of $1.4 \pm 1.1 \mathrm{~kg}$.

\section{Discussion}

The aim of this review was to perform a qualitative and quantitative assessment of literature data on the effects AAS use on lipid profile and muscle hypertrophy in resistance training practitioners. The qualitative analysis showed that the studies included in this review did not have a low risk of bias. In the meta-analysis, the results were conflicting for the evaluated outcomes.

In the analysis of the six articles that evaluated HDL levels, we found that while three studies showed a decrease, ${ }^{12,21,22}$ the other three did not show significant changes ${ }^{11,23,24}$ and Bhasin et al. ${ }^{11}$ reported a reduction in HDL in the control group. These data are in agreement with a study with individuals in andropause, ${ }^{25}$ which showed that the use of steroids may not be able to promote significant changes in HDL. ${ }^{25}$ Thus, results of this review demonstrate that the existing studies on the effect of AAS on HDL levels indicate conflicting results. 


\begin{tabular}{|c|c|c|c|c|c|c|c|c|c|c|c|c|}
\hline \multirow[b]{2}{*}{ Study or Subgroup } & \multicolumn{3}{|c|}{ AAS } & \multicolumn{3}{|c|}{ Control } & \multicolumn{3}{|c|}{ Mean Difference } & \multirow{2}{*}{\multicolumn{3}{|c|}{$\begin{array}{c}\text { Mean Difference } \\
\text { IV, Random, } 95 \% \mathrm{Cl}[\mathrm{mg} / \mathrm{dll}]\end{array}$}} \\
\hline & Mean [mg/dl] & SD [mg/dl] & Total & Mean [mg/dl] & $\mathrm{SD}[\mathrm{mg} / \mathrm{dl}]$ & Total & Weight & N, Random, $95 \% \mathrm{Cl}[\mathrm{mg} / \mathrm{dll}]$ & & & & \\
\hline Bhasin et al, 1996 & -21 & 9.5 & 10 & -1 & 12.9 & 8 & $40.3 \%$ & $-20.00[-30.70,-9.30]$ & & -1 & & \\
\hline Hartgens et al., 2004 & -0.88 & 20.8 & 9 & 14.16 & 31.7 & 7 & $13.8 \%$ & $-15.04[-42.17,12.09]$ & & & & \\
\hline King et al., 1999 & -27.43 & 10.9 & 9 & -18.58 & 16 & 10 & $36.4 \%$ & $-8.85[-21.06,3.36]$ & & $\rightarrow$ & & \\
\hline Kuipers et al.,1991 & 26.55 & 42.6 & 8 & 8.85 & 21.3 & 6 & $9.5 \%$ & $17.70[-16.39,51.79]$ & & & & \\
\hline Total $(95 \% \mathrm{Cl})$ & & & 36 & & & 31 & $100.0 \%$ & $-11.68[-23.07,-0.29]$ & & & & \\
\hline \multicolumn{9}{|c|}{$\begin{array}{l}\text { Heterogeneity: } \text { Tau }^{2}=53.90 ; \mathrm{Chi}^{2}=5.20, \mathrm{df}=3(\mathrm{P}=0.16) ; \mathrm{I}^{2}=42 \% \\
\text { Test for overall effect: } Z=2.01(P=0.04)\end{array}$} & -100 & $\begin{array}{l}-50 \\
\text { Lower TG AAS }\end{array}$ & Lowe TG Control & 100 \\
\hline
\end{tabular}

Figure 5 - Effect of androgenic anabolic steroids (AAS) on triglyceride values.

\begin{tabular}{|c|c|c|c|c|c|c|c|c|c|}
\hline \multirow[b]{2}{*}{ Study or Subgroup } & \multicolumn{3}{|c|}{ AAS } & \multicolumn{3}{|c|}{ Control } & \multirow[b]{2}{*}{ Weight } & \multirow{2}{*}{$\begin{array}{l}\text { Mean Difference } \\
\text { IV, Random, } 95 \% \mathrm{Cl}\end{array}$} & \multirow{2}{*}{$\begin{array}{l}\text { Mean Difference } \\
\text { IV, Random, } 95 \% \mathrm{Cl}\end{array}$} \\
\hline & Mean & SD & Total & Mean & SD & Total & & & \\
\hline Bhasin et al, 1996 & 6.05 & 0.45 & 10 & 1.88 & 0.45 & 8 & $29.3 \%$ & $4.17[3.75,4.59]$ & 릅 \\
\hline Broeder et al., 2000 & 1.3219 & 7.0431 & 32 & 0.7 & 5 & 18 & $18.8 \%$ & $0.62[-2.74,3.98]$ & - \\
\hline Granados et al 2014 & 4.65 & 2.06 & 9 & 0.26 & 1.89 & 8 & $25.1 \%$ & $4.39[2.51,6.27]$ & $\longrightarrow-$ \\
\hline King et al., 1999 & 2.9 & 1.55 & 9 & 2.9 & 1.62 & 10 & $26.8 \%$ & $0.00[-1.43,1.43]$ & T \\
\hline Total $(95 \% \mathrm{Cl})$ & & & 60 & & & 44 & $100.0 \%$ & $2.44[0.02,4.86]$ & \\
\hline \multicolumn{9}{|c|}{$\begin{array}{l}\text { Heterogeneity: } \text { Tau }^{2}=5.17 ; \mathrm{Chi}^{2}=34.09, \mathrm{df}=3(\mathrm{P}<0.00001) ;\left.\right|^{2}=91 \% \\
\text { Test for overall effect: } Z=1.97(P=0.05)\end{array}$} & $\begin{array}{ccccc}-10 & -5 & 0 & 5 & 10 \\
\text { Higher Hypert. AAS } & \text { Higher Hypert. Control }\end{array}$ \\
\hline
\end{tabular}

Two studies, by Bhasin et al. ${ }^{11}$ and Granados et al. ${ }^{21}$ reported adverse effects of AAS, such as acne, sensitive nipples, headaches, muscle cramps, dehydration and mood swings. However, Granados et al. ${ }^{21}$ reported non-significant difference in adverse effects reported between groups.

Conflicting results were also observed for the LDL outcome. Among the four studies included, only one showed an increase in LDL levels, ${ }^{21}$ while the others suggested that the use of steroids, in the dosages used, does not promote significant changes in LDL. On the other hand, regarding triglycerides, the meta-analysis of studies that used oral AAS drugs demonstrated a significant decrease in triglyceride levels with the intervention.

Garevik et al. ${ }^{26}$ demonstrated that the use of low doses (125mg) of AAS did not alter the lipid profile, and that changes in this outcome may be directly related to the dose used, even when only one dose was evaluated. This dose-response relationship was also mentioned by Hartgens et al..$^{23}$ In this study, ${ }^{23}$ the authors evaluated two experiments - the use of self-prescribed drugs and dosages versus the use of pre-established dosages that were randomly and blindly distributed. In the first experiment, where volunteers used drugs ad libitum (high doses), changes in HDL were identified, however, triglyceride and total cholesterol did not change. In the randomized double-blind study, no significant changes in HDL and triglycerides values were observed after eight weeks of nandrolone decanoate (200 mg/week). Thus, the dose-response relationship was reported at the end of the study.

However, many studies that reported this doseresponse relationship were case studies and crosssectional studies, that is, the evidence may still be contradictory. ${ }^{27-29}$ While changes in the lipid profile have been demonstrated with the use of oral AAS in randomized clinical trials, such as reduced HDL-c $\mathrm{c}^{12,21,22}$ and increased LDL-c, ${ }^{21}$ other randomized controlled trials, which used predominantly injectable substances, had negative results. ${ }^{11,23,24}$

Possible metabolic changes may be related to the dosage and the type of substance used. It has been shown that the dose used without medical advice is greater than the therapeutic doses used in most clinical trials and 
Table 1 - Characteristics of the included studies

Objective / Sample (n, sex
and age) Duration and intervention $\quad$ Drug/dosage Hesult $\quad$ Hypertrophy

To determine whether supraphysiological doses of testosterone, taken alone or in conjunction with Bhasin et a standardized strength al.(9) training exercise program increase strength, fat-free mass and muscle mass in normal men
RCT: 10 Weeks; 35 male practitioners (19-40 years) 4 groups (9 PGWE, 8 SGWE, 8 PPEG, 10 SPEG); 4 control weeks, 10 weeks treatment and 16 weeks recovery
SG: Testosterone enanthate $600 \mathrm{mg}$

$$
\text { week }
$$

PG: Sesame oil
SPEG: $\uparrow$ FFM $^{*}$

PPEG: $\downarrow$ HDL; $\leftrightarrow$ TG, LDL e $\mathrm{HB}$
To determine the acute and chronic effect of oral

Androstenedione on

King et al. testosterone levels, skeletal

(10) muscle fiber size, strength

and examine its effect on

blood lipids and liver function markers.
RCT. 19 sedentary men (19-29 years); 2 groups PG:10, SG:9,

RT: 8 weeks, $3 x /$ week
Androstenedione SG: $300 \mathrm{mg} /$ day PG: $250 \mathrm{mg}$ (rice flour) $\leftrightarrow$ FFM $^{*}$

between

groups
SG: $\downarrow$ HDL $(12 \%)$
To investigate the effects of two different EAA

Hartgens et regimens on serum lipids and al.(20) lipoproteins and recovery

of these variables after drug withdrawal.
Study 1 (open). 35 men, 2 groups $(\mathrm{CG}+\mathrm{SG}), \mathrm{SG}: \mathrm{n}=10$

Use/14week, n=9. Use/14week CG: $n=16$. BG performed RT. Self-administered AAS. Study 2 (RCT). 16 men (20-45 years). SG: $\mathrm{n}=9$, PG: $\mathrm{n}=7$. RT: 8 weeks, $7-9 \mathrm{~h} /$ week Dosages during and 6 weeks after stopping use
Study 1

Uncontrolled doses.

Stanozolol,

Drostanolone,

Testosterone,

Clenbuterol,

Testosterone

cypionate,

Nandrolone

decanoate, etc.

Study 2. SG:

Nandrolone

decanoate

(200mg), PG:

Peanut oil.
Study 1 . SG: $\downarrow$ HDL, $\downarrow$ HDL2, $\downarrow$ HDL3, $\leftrightarrow \mathrm{TG}, \leftrightarrow \mathrm{TC}$

CG: $\leftrightarrow$

Study 2. $\leftrightarrow$ HDL, HDL2, HDL3

$\leftrightarrow \mathrm{TG}, \leftrightarrow \mathrm{TC}$

To elucidate the physiological
Broeder et al.
$\begin{aligned} & \text { and hormonal effects of } \\ & \text { androstenediol and oral } \\ & \text { androtenedione in men }\end{aligned}$

Broeder et al.
(19) and hormonal effects of
androstenediol and oral androtenedione in men

\author{
RCT. 50 men ${ }^{\S}$ (35-65 years) \\ PG: 18 \\ GDiol: 17 \\ GDione: 15
}

RT: 12 weeks, 3x/week

\section{PG: Maize starch GDione: $200 \mathrm{mg}$ / day}

GDiol: 200mg/day
NE

$$
\begin{gathered}
\leftrightarrow \text { FFM }^{\$} \\
\text { between } \\
\text { groups }
\end{gathered}
$$$$
\leftrightarrow \mathrm{HDL}, \leftrightarrow \mathrm{TG}
$$

PG: Maltodextrin

$$
\text { SG: } 110 \mathrm{mg}
$$

Androstenedione

$50 \mathrm{mg}$ of bergamotine
GP: 8
GU: 9

RT: 4 weeks, $4 x /$ week
To examine the effects of anabolic steroids on body composition, muscle fiber

Kuipers et al dimensions, liver function and (21) risk factors for cardiovascular disease in experienced and healthy bodybuilders.

$\begin{array}{cc}\text { ECR. } 14 \text { men (18-45 years) } & \text { PG: Placebo UN } \\ \text { SG: } 6 & \text { SG: } 200 \mathrm{mg} / \text { week } \\ \text { PG: } 8 & \text { Nandrolone } \\ \text { RT: } 8 \text { weeks, } 3-4 x / \text { week } & \text { Decanoate }\end{array}$

$$
\uparrow \mathrm{FFM} \quad \leftrightarrow \mathrm{HDL}, \leftrightarrow \mathrm{LDL}, \leftrightarrow \mathrm{TG}
$$

RCT: randomized clinical trial; SG: steroid group; PG: placebo group; PGWE: placebo group without exercise; SGWE: steroid group without exercise; PPEG: placebo plus exercise group; SPEG: steroid plus exercise group; GDiol: androstenediol; GDione: androstenedione; CG: control group; BG: both groups; TG: Triglycerides; TC: Total cholesterol; HB: hemoglobin; RT: resistance training; NE: Did not evaluate LDL; FFM: fat free mass; \#: hydrostatic weighing; \$: DEXA; $\uparrow:$ increase; $\leftrightarrow:$ no difference; $\downarrow$ : UN: unreported; $\S:$ Did not report physical activity status of participants; ${ }^{a}:$ muscle biopsy; The level of significance adopted in the studies was $5 \%$ 
that high doses can promote metabolic changes, unlike the usual therapeutic doses..$^{23,26,30}$ Although therapeutic doses can vary from $50 \mathrm{mg}$ to $144 \mathrm{mg}$ per day, ${ }^{31}$ the usual doses for aesthetic purposes exceed 1000mg per week. ${ }^{23}$ In addition, the oral use of AAS, especially 17-alphaalkylated AAS, can affect liver metabolism, as they undergo first-pass metabolism, ${ }^{32,33}$ thereby promoting more marked changes.

Lipoproteins are influenced by the activity of hepatic lipase, with formation of smaller and denser particles. ${ }^{34}$ An overexpression of hepatic lipase has a negative impact on plasma values of HDL-c and LDL-c, and increases the hepatic cholesterol concentrations without altering bile cholesterol secretion. ${ }^{35,36}$ Therefore, hepatic lipase plays an essential role in the negative regulation of HDL-c levels.

Changes in lipid profile are known to increase cardiovascular risk, which can be aggravated by other factors such as obesity and physical inactivity. ${ }^{37-40}$ Usually, these risk factors are not present in individuals who use steroids for aesthetic or competitive purposes. However, some cardiovascular changes could be identified among users, such as increased blood pressure, ${ }^{1}$ ventricular hypertrophy, ${ }^{41}$ and endocrine changes, such as hypogonadism, ${ }^{42,43}$ which can cause chronic infertility. ${ }^{44,45}$ However, as in lipid variables, there are controversies about echocardiographic results, as demonstrated by Hartgens et al. ${ }^{46}$

When assessing hypertrophic gain, no significant change was identified in the overall analysis. Although this was not the main objective of this review, the analysis of hypertrophic gains was important to demonstrate that, although the use of AAS did not significantly alter the lipid profile, the doses used were also unable to promote the changes expected by the users. Considering that one of the main factors for the non-therapeutic use of AAS is the concern with physical appearance, ${ }^{47}$ hypertrophic gain is the main objective of recreational users. This may justify the high doses used in non-therapeutic situations.

It should be noted that the studies did not present the sample size calculation and did not report the sample power. The study by Broeder et al..$^{22}$ presents sample calculation, however, it did not describe for which outcome it was calculated. In addition, the study showed a loss of follow-up of $29 \%$, which did not affect the sample power due to the high number of individuals included initially. ${ }^{22}$ All studies were susceptible to the bias of multiple comparisons, since they did not clearly present the main outcome assessed.

The gray literature and clinical trial records were not accessed for this review. In addition, there was a risk of bias in the included studies, which limits the extrapolation of the results.

\section{Pratical Applications}

We conclude that current evidence does not support an effect of low-to-moderate doses of AAS on HDL-c and LDL-c levels. In addition, the use of AAS, in the doses used in clinical trials, had no beneficial effect on muscle hypertrophy.

\section{Author Contributions}

Conception and design of the research: Tenório MCC, Correia L, Paz C. Acquisition of data: Tenório MCC, Paz C, Guimarães Junior M, Valladares F. Analysis and interpretation of the data: Tenório MCC, Correia L, Paz C. Statistical analysis: Tenório MCC, Correia L, Paz C. Writing of the manuscript: Tenório MCC, Correia L, Paz C. Critical revision of the manuscript for intellectual content: Tenório MCC, Correia L, Valladares F, de Sá C.

\section{Potential Conflict of Interest}

No potential conflict of interest relevant to this article was reported.

\section{Sources of Funding}

This study was partially funded by CAPES.

\section{Study Association}

This article is part of the doctoral thesis submitted by Mario Cesar Carvalho Tenório, from Escola Bahiana de Medicina e Saúde Pública.

\section{Ethics Approval and Consent to Participate}

This article does not contain any studies with human participants or animals performed by any of the authors. 


\section{References}

1. Achar S, Rostamian A, Narayan SM. Cardiac and metabolic effects of anabolic-androgenic steroid abuse on lipids, blood pressure, left ventricular dimensions, and rhythm. Am J Cardiol. 2010;106(6):893-901.

2. Lippi G, Guidi G, Ruzzenente O, Braga V, Adami S. Effects of nandrolone decanoate (Decadurabolin) on serum Lp(a), lipids and lipoproteins in women with postmenopausal osteoporosis. Scand J Clin Lab Invest. 1997;57(6):507-11.

3. Rahnema CD, Crosnoe LE, Kim ED. Designer steroids - over-the-counter supplements and their androgenic component: review of an increasing problem. Andrology. 2015;3(2):150-5.

4. Joseph JF, Parr MK. Synthetic Androgens as Designer Supplements. Curr Neuropharmacol. 2015;13(1):89-100.

5. Sagoe D, Molde H, Andreassen CS, Torsheim T, Pallesen S. The global epidemiology of anabolic-androgenic steroid use: a meta-analysis and meta-regression analysis. Ann Epidemiol. 2014;24(5):383-98.

6. Fraga A, Ladeia A, de Sá C, Tenório M. Efeito do exercício sobre os níveis de hdl-c: uma revisão sistemática de metanálises. Rev Bras Med Esporte. 2017;23(6):488-94.

7. Souza FR, Dos Santos MR, Porello RA, Fonseca GWPD, Sayegh ALC, Lima TP, et al. Diminished Cholesterol Efflux Mediated by HDL and Coronary Artery Disease in Young Male Anabolic Androgenic Steroid Users. Atherosclerosis. 2019;283.

8. Vigen R, O'Donnell CI, Baron AE, Grunwald GK, Maddox TM, Bradley $\mathrm{SM}$, et al. Association of testosterone therapy with mortality, myocardial infarction, and stroke in men with low testosterone levels. Jama. 2013;310(17):1829-36.

9. Morgentaler A, Miner MM, Caliber M, Guay AT, Khera M, Traish AM. Testosterone therapy and cardiovascular risk: advances and controversies. Mayo Clin Proc. 2015;90(2):224-51.

10. Moraes DR, Castiel LD, Ribeiro AP. ["No" for stacked young bodybuilders, "yes" for manthers: the biomedical discourse on anabolic steroids and health]. Cad Saude Publica. 2015;31(6):1131-40.

11. Bhasin S, Storer TW, Berman N, Callegari C, Clevenger B, Phillips J, et al. The effects of supraphysiologic doses of testosterone on muscle size and strength in normal men. N Engl J Med. 1996;335(1):1-7.

12. King DS, Sharp RL, Vukovich MD, Brown GA, Reifenrath TA, Uhl NL, et al. Effect of oral androstenedione on serum testosterone and adaptations to resistance training in young men: a randomized controlled trial. Jama. 1999;281(21):2020-8.

13. Hartgens F, Kuipers H. Effects of androgenic-anabolic steroids in athletes. Sports Med. 2004;34(8):513-54.

14. Hoffman JR, Ratamess NA. Medical Issues Associated with Anabolic Steroid Use: Are They Exaggerated? J Sports Sci Med. 2006;5(2):182-93.

15. Solimini R, Rotolo MC, Mastrobattista L, Mortali C, Minutillo A, Pichini $\mathrm{S}$, et al. Hepatotoxicity Associated With Illicit Use of Anabolic Androgenic Steroids in Doping. European review for medical and pharmacological sciences. 2017;21(1 Suppl).

16. The PRISMA statement for reporting systematic reviews and metaanalyses of studies that evaluate health care interventions: explanation and elaboration. 2009;62(10):e1-e34.

17. Higgins jpt, Green S. 16.1.3.2 Imputing standard deviations for changes from baseline. 2011. In: Cochrane Handbook for Systematic Reviews of Interventions [Internet]. Available from: http://handbook.cochrane.org/.

18. Higgins JP, Altman DG, Gotzsche PC, Juni P, Moher D, Oxman AD, et al. The Cochrane Collaboration's tool for assessing risk of bias in randomised trials. BMJ. 2011;343:d5928.

19. Higgins J, Green S. Cochrane Handbook for Systematic Reviews of Interventions Version 5.1.0 [updated March 2011]. . The Cochrane Collaboration, 2011. ed. Available from http://handbook.cochrane.org.: The Cochrane Collaboration, 2011.; 2011.
20. Lee E, Dobbins M, Decorby K, McRae L, Tirilis D, Husson H. An optimal search filter for retrieving systematic reviews and meta-analyses. BMC Med Res Methodol. 2012;12:51.

21. Granados J, Gillum TL, Christmas KM, Kuennen MR. Prohormone supplement 3beta-hydroxy-5alpha-androst-1-en-17-one enhances resistance training gains but impairs user health. J Appl Physiol (1985). 2014;116(5):560-9.

22. Broeder CE, Quindry J, Brittingham K, Panton L, Thomson J, Appakondu $S$, et al. The Andro Project: physiological and hormonal influences of androstenedione supplementation in men 35 to 65 years old participating in a high-intensity resistance training program. Arch Intern Med. 2000;160(20):3093-104.

23. Hartgens F, Rietjens G, Keizer HA, Kuipers H, Wolffenbuttel BH. Effects of androgenic-anabolic steroids on apolipoproteins and lipoprotein (a). Br J Sports Med. 2004;38(3):253-9.

24. Kuipers H, Wijnen JA, Hartgens F, Willems SM. Influence of anabolic steroids on body composition, blood pressure, lipid profile and liver functions in body builders. Int J Sports Med. 1991;12(4):413-8.

25. Zajac A, Wilk M, Socha T, Maszczyk A, Chycki J. Effects of growth hormone and testosterone therapy on aerobic and anaerobic fitness, body composition and lipoprotein profile in middle-aged men. Ann Agric Environ Med. 2014;21(1):156-60.

26. Garevik N, Rane A, Bjorkhem-Bergman L, Ekstrom L. Effects of different doses of testosterone on gonadotropins, 25-hydroxyvitamin D3, and blood lipids in healthy men. Subst Abuse Rehabil. 2014;5:121-7.

27. McNutt RA, Ferenchick GS, Kirlin PC, Hamlin NJ. Acute Myocardial Infarction in a 22-year-old World Class Weight Lifter Using Anabolic Steroids. The American journal of cardiology. 1988;62(1).

28. Fineschi V, Riezzo I, Centini F, Silingardi E, Licata M, Beduschi G, et al. Sudden Cardiac Death During Anabolic Steroid Abuse: Morphologic and Toxicologic Findings in Two Fatal Cases of Bodybuilders. International journal of legal medicine. 2007;121(1)

29. Angell PJ, Ismail TF, Jabbour A, Smith G, Dahl A, Wage R, et al. Ventricular Structure, Function, and Focal Fibrosis in Anabolic Steroid Users: A CMR Study. Eur J Appl Physiol. 2014;114(5):48-53.

30. Severo CB, Ribeiro JP, Umpierre D, Da Silveira AD, Padilha MC, De Aquino Neto FR, et al. Increased atherothrombotic markers and endothelial dysfunction in steroid users. Eur J Prev Cardiol. 2013;20(2):195-201.

31. Yabluchanskiy A, Tsitouras PD. Is Testosterone Replacement Therapy in Older Men Effective and Safe? Drugs Aging. 2019;36(11):981-9.

32. Neri M, Bello S, Bonsignore A, Cantatore S, Riezzo I, Turillazzi E, et al. Anabolic androgenic steroids abuse and liver toxicity. Mini Rev Med Chem. 2011;11(5):430-7.

33. Pope HG, Wood RI, Rogol A, Nyberg F, Bowers L, Bhasin S. Adverse Health Consequences of Performance-Enhancing Drugs: An Endocrine Society Scientific Statement. Endocrine reviews. 2014;35(3).

34. Annema W, Tietge UJ. Role of Hepatic Lipase and Endothelial Lipase in High-Density Lipoprotein-Mediated Reverse Cholesterol Transport. Current atherosclerosis reports. 2011;13(3).

35. Kobayashi J, Miyashita K, Nakajima K, Mabuchi H. Hepatic Lipase: A Comprehensive View of Its Role on Plasma Lipid and Lipoprotein Metabolism. Journal of atherosclerosis and thrombosis. 2015;22(10).

36. Yasuda T, Ishida T, Rader DJ. Update on the Role of Endothelial Lipase in High-Density Lipoprotein Metabolism, Reverse Cholesterol Transport, and Atherosclerosis. Circulation J.2010;74(11):2263-70.

37. Baigent C, Blackwell L, Emberson J, Holland LE, Reith C, Bhala N, et al. Efficacy and safety of more intensive lowering of LDL cholesterol: a meta-analysis of data from 170,000 participants in 26 randomised trials. Lancet. 2010;376(9753):1670-81. 
38. Xavier HT, Izar MC, Faria Neto JR, Assad MH, Rocha VZ, Sposito AC, et al. [V Brazilian Guidelines on Dyslipidemias and Prevention of Atherosclerosis]. Arq Bras Cardiol. 2013;101(4 Suppl 1):1-20.

39. Parish S, Offer A, Clarke R, Hopewell JC, Hill MR, Otvos JD, et al. Lipids and lipoproteins and risk of different vascular events in the MRC/BHF Heart Protection Study. Circulation. 2012;125(20):2469-78.

40. Poirier P, Giles TD, Bray GA, Hong Y, Stern JS, Pi-Sunyer FX, et al. Obesity and cardiovascular disease: pathophysiology, evaluation, and effect of weight loss. Arterioscler Thromb Vasc Biol. 2006;26(5):968-76.

41. Karila TA, Karjalainen JE, Mantysaari MJ, Viitasalo MT, Seppala TA. Anabolic androgenic steroids produce dose-dependant increase in left ventricular mass in power atheletes, and this effect is potentiated by concomitant use of growth hormone. Int J Sports Med. 2003;24(5):337-43.

42. Coward RM, Rajanahally S, Kovac JR, Smith RP, Pastuszak AW, Lipshultz LI. Anabolic steroid induced hypogonadism in young men. J Urol. 2013;190(6):2200-5
43. Rahnema CD, Lipshultz LI, Crosnoe LE, Kovac JR, Kim ED. Anabolic steroid-induced hypogonadism: diagnosis and treatment. Fertil Steril. 2014;101(5):1271-9.

44. de Souza GL, Hallak J. Anabolic steroids and male infertility: a comprehensive review. BJU Int. 2011;108(11):1860-5.

45. Kanayama G, Hudson JI, DeLuca J, Isaacs S, Baggish A, Weiner R, et al. Prolonged hypogonadism in males following withdrawal from anabolic-androgenic steroids: an under-recognized problem. Addiction. 2015;110(5):823-31.

46. Hartgens F, Cheriex EC, Kuipers H. Prospective echocardiographic assessment of androgenic-anabolic steroids effects on cardiac structure and function in strength athletes. Int J Sports Med. 2003;24(5):344-51.

47. Griffiths S, Jacka B, Degenhardt L, Murray SB, Larance B. Physical appearance concerns are uniquely associated with the severity of steroid dependence and depression in anabolic-androgenic steroid users. Drug Alcohol Rev. 2018;37(5):664-70. 